\title{
HISTÓRIA DE VIDA LABORAL E APOSENTADORIA: UMA METODOLOGIA EM DISCUSSÃO
}

\author{
LABOR LIFE HISTORY AND RETIREMENT: DISCUSSING A METHODOLOGY \\ HISTORIA DE VIDA LABORAL JUBILACIÓN. UNA METODOLOGÍA EN DISCUSSIÓN
}

Teresa Cristina Carreteiro*

\begin{abstract}
RESUMO
O texto aborda a historia de vida na perspectiva da psicossociologia. Em um primeiro tempo discute aspectos primordiais para que a realização deste trabalho possa ocorrer: o engajamento do participante, do profissional e a escuta clinica plural. Em um segundo tempo enfoca a historia de vida laboral na vertente da narrativa da aposentadoria. A hipótese é que a aposentadoria constitui uma ruptura na trajetória de vida e sugere que o advento deste momento requer um olhar atento à historia de vida laboral.
\end{abstract}

Palavras-chave: História de vida laboral. Aposentadoria. Metodologia. Psicossociologia.

\begin{abstract}
The text approaches life history from a psycho-sociological perspective. In a first moment it discusses primeval aspects so that this work may occur: the engagement of both the participant and the professional, and a plural clinical listening. In a second moment is focusses labor life history as seen from the retirement's narrative viewpoint. The hypothesis is that retirement constitutes a rupture in life course and suggests that the advent of this moment demands a watchful regard to labr life history.
\end{abstract}

Keywords: Labor life history. Retirement. Methodology. Psychosociology.

\section{RESUMEN}

El texto aborda la historia de la vida en la perspectiva de la psicosociología. En un primer tiempo, discute aspectos primordiales para que la realización de este trabajo pueda ocurrir: el compromiso del participante, del profesional y la escucha clínica plural. En un segundo tiempo, enfoca en la historia de vida laboral vista por la vertiente de la narrativa de la jubilación. El hipotesis es que la jubilación constituye una ruptura en la trayectoria de vida y sugiere

\footnotetext{
* Doutora em Psicologia Social Clinica, Universidade de Paris 7; Pós doutorado em Sociologia Universidade Paris 7; Professora do Programa de pós graduação em Psicologia da Universidade Federal Fluminense (UFF); pesquisadora do Conselho Nacional de Desenvolvimento Científico e Tecnológico CNPq.; membro fundadora do Centre International de Recherche, Formation et d'Intervention en Psychosociologique (CIRFIP). E-mail: tecar2@uol.com.br
} 
que este momento requiere una mirada atenta a la historia de vida laboral.

Palabras clave: Historia de vida laboral. Jubilación. Metodología. Psicosociología.

\section{INTRODUÇÃO}

A história de vida teve sua inscrição no campo das ciências humanas com a Escola de Chicago (Coulon, 1994; Carreteiro, 2003). Desde então ela tem sido utilizada de modos diferentes por várias disciplinas (história, psicologia, sociologia, antropologia). Não é nosso propósito retomar neste artigo todas as suas distinçôes, métodos e teorizaçôes, mas explorar a metodologia da história de vida laboral na perspectiva da psicossociologia.

\section{PSICOSSOCIOLOGIA E METODOLOGIA DA HISTÓRIA DE VIDA LABORAL}

A psicossociologia analisa as interações existentes entre os aspectos subjetivos, familiares, sociais, organizacionais, históricos (Pinto, Carreteiro \& Rodriguez, 2015), destacando contradições, conflitos e pontos de articulação entre várias dimensóes que atravessam o estudo ou a pesquisa sobre um campo preciso. As metodologias qualitativas que emprega são bastante variadas, pois, tratando-se de um método atento à clínica, baseia-se na escuta (Carreteiro\& Barros, 2011). A metodologia não é dada a priori, ela é fruto da multiplicidade de ângulos que podem se desdobrar a partir da escuta. Caberá ao profissional discernir qual ou quais dimensões devem ser destacadas para a construção metodológica. Nos tópicos seguintes discutiremos dois aspectos importantes em qualquer objeto de pesquisa. Eles são incontornáveis para se pensar em metodologias ou intervenções no âmbito: o lugar do sujeito participante e a escuta plural.

\section{PARTICIPANTE: UM SUJEITO ATIVO}

O participante da pesquisa é considerado um sujeito ativo. Essa denominação pode ser desdobrada em várias dimensões:

a) Sujeito engajado: ele terá um importante papel no desenvolvimento da pesquisa-intervenção, contribuindo com suas reflexôes, críticas e diferentes posicionamentos. Tratando-se de pesquisa atenta à singularidade, o nível de implicação de cada participante é único. $\mathrm{O}$ engajamento pessoal significa estar ciente de que a pesquisa-intervenção só alcançará resultados satisfatórios se houver da parte dos que a demandam um empenho 
psíquico. Isso significa sensibilidade à temática abordada, um interesse ou ainda um sentimento de mal-estar, despertando o desejo de compreender melhor situaçôes vividas, o que leva a considerá-lo um co-construtor da pesquisa.

b) Sujeito inconsciente: o sujeito é apreendido na sua complexidade, no fazer, na reflexão e no atravessamento inconsciente nas realizações e ações. Duas pulsões se fazem presentes: a epistemofílica (Freud, [1905]/(1996); Enriquez,1993) e a de domínio. A primeira se volta para a interrogação, a dúvida, o interesse em conhecer e compreender. A segunda nega a importância do aprofundamento da interrogação e se apoia no desejo de controlar (Enriquez, 1993). A expressão dessa pulsão quer encontrar explicações sem fissuras, que sejam definitivas, únicas e totalizantes. A escuta deve estar atenta às expressões dessas duas pulsões, à presença de movimentos que busquem a autonomia ou, ao contrário, a heteronomia (Castoriadis, 1982). A dinâmica pulsional é sempre ativa e requer uma atenção constante.

c) Sujeito social: todo indivíduo se constrói sempre em interação com um coletivo, grupos, instituições, em um tempo histórico, político e social. Todo sujeito é bio- psico-social (Barus-Michel, 2004).

A pesquisa-intervenção considera que há um saber que é produzido pela experiência direta dos atores, tanto dos profissionais quanto dos participantes. Ela recusa a ruptura entre saber profano e saber científico. Os conhecimentos profanos e acadêmicos são fruto de contextos sócio-históricos de produção, sejam eles de especialistas ou de sujeitos que os adquirem no exercício de atividades diversas, sem que tenha ocorrido por via científica. Afirma-se, desse modo, a potência dos sujeitos. Todos os saberes são valorizados, não se criando escalas valorativas em relação a eles. O psicossociólogo deve estar atento a esse aspecto, visto que sua prática se opõe àquelas que são fruto do imaginário atual reinante, o qual diferencia as diversas especialidades e despreza os conhecimentos que não sejam adquiridos por certificações.

$\mathrm{Na}$ perspectiva psicossociológica há um diálogo contínuo entre prática e teoria, desenhando uma relação circular e um movimento permanente (Gratton, Lainé, \&Trekker, 2016).

\section{ESCUTA CLINICA PLURAL}

Toda escuta se faz a partir da narrativa de um sujeito ou de um grupo. Quanto ao sujeito, ele é singular, visto que as soluçóes que encontra para fazer face a sua 
existência são únicas; ele também é social, as situações que experimenta não são somente próprias a ele, são fruto de atravessamentos produzidos na dinâmica social por outros sujeitos, grupos, instituições, organizações, em um tempo sócio-histórico. Nessa perspectiva é que se pode afirmar a marca psicossocial que todo sujeito porta. Desse modo, a psicossociologia estará atenta ao feixe de interações que atravessam os sujeitos, os grupos, os coletivos e as instituições.

A escuta clinica pode destacar um ou vários desses aspectos e suas interações. É nesse sentido que se enfatiza o aspecto plural da escuta. No entanto, essa escuta, apesar de conseguir identificar um conjunto de dimensões, deverá escolher quais são mais importantes para a situação objeto de uma intervenção, de uma pesquisa ou de uma pesquisa-intervenção. Isso se vincula aos sentidos que possam ser mais significativos na elaboração da demanda. É a partir da escuta da demanda que a metodologia será concebida.

\section{HISTÓRIA DE VIDA LABORAL}

No campo do trabalho, em algumas situações específicas, temos privilegiado a história de vida laboral. Seu emprego, na perspectiva individual, tem ocorrido quando uma reflexão sobre a trajetória se faz oportuna. Nesse sentido, os momentos mais propícios são aqueles em que sucede um forte movimento, uma ruptura ou uma mudança na trajetória de vida de trabalho. Aqui podemos pensar em desemprego, aposentadoria, licenças de saúde, mudanças, sofrimentos originários pelo trabalho, entre outros.

Cabe a discussão sobre o termo história. Sua etimologia remete ao grego e significa "testemunha". O termo é, geralmente, empregado em referência a ocorrências passadas. A história laboral coloca em destaque não só os eventos vividos, mas também os sentidos que têm para o sujeito narrador, como ele os interpreta e que valores lhes atribui.

A história de vida não é um recontar monocórdico, enfatizando sempre da mesma maneira algo ocorrido em determinado tempo; ao contrário, a narração é sempre dinâmica, podendo assumir diferentes modulações e interpretações. As formas de narrar, interpretar, compreender fatos, intercalar ou esquecer eventos são fruto do atravessamento de muitas variáveis. Podem-se elencar algumas, mas sempre existirão outras que escaparão. Entre um fato sucedido e o tempo da narração, há o advento de uma série de acontecimentos que influem na reconstrução dos significados que lhe são atribuídos e, logo, na forma da narratividade. 
$\mathrm{Na}$ metodologia da história de vida, a narrativa é construída face a um interlocutor. $\mathrm{O}$ vínculo que se estabelece com ele vai inferir na narrativa, no desejo de contar, de refletir sobre zonas conhecidas ou desconhecidas da experiência. O profissional pode funcionar como testemunho da narratividade, aquele que auxilia a criar condições, por sua escuta e interesse, ao aprofundamento de outros aspectos da experiência. A escuta permite a construção de sentidos, além dos que eram conhecidos anteriormente. Em síntese, a narrativa é tributária de duas temporalidades: a do tempo presente e a do tempo experiencial. O tempo presente inclui o contexto em que a produção narrativa se faz. O tempo experiencial é trabalhado também pela dimensão psíquica e sua articulação com o tempo histórico, social, organizacional, familiar e outros. A imbricação dessas duas temporalidades permite apreender várias significações e formas de narrativas. Pode-se dizer que haverá uma rememoração ativa e, portanto, que toda rememoração será sempre uma reconstrução (Freud, 1975).

O termo história de vida merece ser discutido. A vida em si não é uma história, ela é uma sucessão de eventos. É o olhar retrospectivo que lhe atribui sentido e traça paralelo entre fatos, dimensões, afetos e circunstâncias. A capacidade narrativa é uma função humana, ela é fruto do trabalho psíquico do sujeito.

A história pode ser vista por múltiplas lentes. Ela é a de um narrador, se a vemos unicamente sob um prisma individual. No entanto, se ampliarmos as lentes, ela o ultrapassa, visto condensar elementos de um grupo social e de um contexto.

Quando se trata de história de vida que busca enfocar determinado ângulo, como no caso deste texto, ou seja, o trabalho, a narrativa do sujeito se construirá em torno da questão pesquisada. A história de vida, explicitada através da narrativa, terá dois polos mediadores entre o sujeito e o que é narrado. O primeiro é o objeto sobre o qual se constrói a narrativa, no caso atual, o trabalho ou algum aspecto mais específico dele. Essa mediação imprime um delineamento na reflexão. O segundo polo mediador é o profissional que, por sua presença e escuta, participa como um dos elementos que delimitam o campo narrativo.

A atenção de ambos, participante e profissional, se volta para o campo sujeitotrabalho. O psicossociólogo, através da escuta plural, mantém uma atenção compreensiva ao narrador-trabalhador. Ele intervém em momentos que possam auxiliar a desbloquear certas dificuldades experimentadas pelo sujeito ou quando sente necessidade de precisões. O campo do trabalho é extremamente vasto, e assim, em determinadas investigações, poderão ser feitos recortes. Em outras, o objeto da pesquisa terá um destaque especial. 
Passaremos agora a uma pesquisa em curso sobre aposentadoria. O objetivo será apontar como a história laboral foi concebida como enquadre metodológico e justificar essa escolha.

\section{HISTÓRIA DE VIDA LABORAL E APOSENTADORIA}

Os sentidos atribuídos à aposentadoria são múltiplos e vinculados a questōes psicossociais, que se situam na articulação de muitos campos (psíquico, social, político, econômico, histórico e jurídico). Na perspectiva da singularidade, a hipótese é que o conjunto dessas questôes associa-se à relação que o aposentado teve com sua trajetória profissional e às significações atribuídas à ruptura marcada pela aposentadoria.

O interesse da pesquisa está em compreender as acepções do trabalho e da aposentadoria no serviço público para professores universitários. O recorte do público deve-se ao fato de os trabalhadores poderem se aposentar, ao atingir o número de anos suficiente para gozar desse benefício e receber aposentadoria integral, ou seja, aquela que a princípio propicia nível salarial mais ou menos compatível com o que tinham anteriormente ${ }^{1}$. Essa situação é bastante diferente da aposentadoria no setor privado. Tal fato mostra a importância do quadro legal. A institucionalização cria diferenciações claras nas formas de organizar e de viver as etapas de vida, tanto no nível da estrutura social quanto na forma de construir e projetar cada etapa da própria vida (Kohli \& Künemund, 2012) O quadro legal participa claramente das modalidades de realizar a passagem da vida profissional à aposentadoria.

A história de vida laboral se atém aos sofrimentos e aos prazeres presentes nas trajetórias dos trabalhadores e também às modalidades de viver a aposentadoria. Vale indagar por que, ao se pesquisar a aposentadoria, busca-se levantar o conjunto da vida laboral. Isso se deve ao lugar ocupado pelo trabalho em nossa sociedade. Há autores que questionam se ele ainda teria um papel central (Barel, 1985; Billiard, 1997) na vida das pessoas, enquanto outros insistem em que o trabalho é "o fundamento do vínculo social” (Méda, 2007).

Apesar da complexidade que envolve esse tema, consideramos que o trabalho continua tendo uma dimensão de integração e de centralidade e participa construção subjetiva (Amado \& Enriquez, 2011). Ele interfere na produção de mitos individuais, organizadores da vida dos indivíduos (Enriquez, 1993).

Se o trabalho ocupa um lugar central na vida das pessoas, pode-se interrogar o que ocorre quando deixa de existir, por ocasião da aposentadoria. Para os

1 São notórias, nas reivindicaçôes sindicais, as perdas salariais dos aposentados. Neste projeto, apesar de se abordarem questôes financeiras, elas não serão o centro da investigação. 
aposentados, ele deixa de ser o locus de produção, de certa participação social, de possível reconhecimento, de prazer e de sofrimento.

O trabalho antes organizava o cotidiano, o uso do espaço, do tempo e das relaçóes. O advento da aposentadoria, nesse cenário, é um acontecimento produtor de ruptura que terá ressonância em vários aspectos da vida. Todas as instâncias que tinham o trabalho como eixo primordial serão mobilizadas e sofrerão mudanças (Blanché, 2014).

As questóes levantadas acima nos levam a pensar na metodologia da história de vida, que permite um olhar voltado para a trajetória laboral: a construção do ser trabalhador. A investigação visa abordar os eixos temáticos que possam contemplar a vida de trabalho do entrevistado, o momento da aposentadoria e a pós-aposentadoria.

Essa metodologia, tendo uma dimensão clínica, não impõe uma ordem préestabelecida, cronológica a ser seguida face às temáticas abordadas e ressalta a atenção à dinâmica da entrevista. A relação do pesquisador com cada pessoa produz um processo singular e possibilita que o entrevistado aborde as temáticas investigadas e os significados que lhes atribui de modo único. O psicossociologo se assegurará de que, no final da entrevista, os eixos temáticos tenham sido abordados. Ao mesmo tempo, pode haver o surgimento de novos dados ao longo da entrevista, levantando novos questionamentos.

\section{EIXOS TEMÁTICOS}

\subsection{A trajetória profissional}

Esta se relaciona ao conjunto da vida laboral. Estar-se-á atento ao início da trajetória profissional (planejamentos, escolhas, oportunidades), às funçôes exercidas, à progressão da carreira (Bendassolli, 2009), às atividades, às capacitações e aos cursos realizados. Tais investigações serão sempre acompanhadas das significaçoes que os diferentes momentos do trabalho exercido tiveram e, ainda, dos prazeres e dos sofrimentos (Dejours, 1997) relacionados.

\section{2 $\mathrm{O}$ advento da aposentadoria}

O objetivo é abordar como surge e se concretiza a ideia de aposentadoria. Quais projetos (Sartre, 1976; Carreteiro, 1993) foram sendo construídos para esse momento? Quais vivências acompanham este período? É importante observar se há diferenças entre a aposentadoria pensada e a aposentadoria real. 


\subsection{A pós-aposentadoria}

Como a aposentadoria está sendo vivida? Que sentimentos ela trouxe? Quais mudanças ocorreram na vida, na perspectiva do uso do tempo, do espaço, das relaçōes familiares e de amizade? Que novos projetos foram ou estão sendo construídos e os sentidos que têm sido atribuídos a eles? Quais as proximidades e diferenças que esses projetos mantêm com as atividades profissionais exercidas anteriormente? Como a aposentadoria é vista socialmente pelos familiares, pelos pares e pelo meio social mais amplo? Como os familiares participam e se integram na elaboração de novos projetos? Como os aspectos financeiros têm participado no cotidiano da aposentadoria e nos projetos elaborados?

\section{O LUGAR DA HISTORICIDADE NA NARRATIVA}

O contar a história laboral requer um desejo, o que permitirá que ela não seja um acontecimento burocratizado, mas um acontecimento vivo. É importante ter zelo com as situações que circunscrevem a entrevista (o lugar, a privacidade), assim como com a escuta. Escutar requer presença, cuidado e uma atenção à pessoa, ao que é dito e expresso.

De modo geral o exercício da história de vida cria uma diferença no curso do cotidiano. Não é habitual ter atenção a um eixo de vida e explaná-la para um outro que está ali presente para escutar. Nesse aspecto, pode-se dizer que a entrevista produz uma ruptura com o cotidiano. Essa situação é aparentemente nova ou inabitual. Ela pode ter se tornado presente em outros momentos, quando o sujeito se sentiu desamparado ou estressado e questionou suas formas de reagir a situações difíceis ou sobre sua própria vida. Nessas ocasiōes, pode ter demandado a um outro, em quem confiava, uma escuta ou ajuda. Quanto mais o sujeito é capaz de se questionar, mais ele poderá se investir em uma pesquisa sobre a história de vida.

Cada sujeito se apropria diferentemente de sua história. O narrar a um outro pode levar à percepção de aspectos novos e reforçar ou ignorar outros. Nesse sentido, a narração engajada participa de outras apropriações e significações. No entanto, não se pode afirmar a priori o que vai ocorrer no processo da historicidade. Cada pessoa reage diferentemente. Mas a narração será sempre única, ela nunca é feita da mesma maneira, ela sempre será uma reconstrução, como dissemos. Pode-se pensar na existência de vários níveis de reconstrução, implicando conscientizações diferentes, relação entre elementos que poderiam parecer desconexos, sínteses elaborativas ou explicativas. Pode haver surpresa face a elementos narrativos que escapam a nosso controle, surgindo lapsos de linguagem ou outras figuras que surpreendam. Na verdade, quaisquer que sejam os elementos solicitados pela narrativa, sempre haverá uma reconstrução. 
Cada pessoa, ao longo da narrativa, se reapropria e remaneja três elementos fundamentais de sua vida: a crônica, a epopeia e o mito (Enriquez, 2003).

A crônica é composta pelos eventos importantes da vida; a epopeia, mais ou menos imaginária, é produzida quando se debruça sobre o desenvolvimento da vida, visto que cada ser humano é para si mesmo um herói, no sentido freudiano, alguém que em momentos precisos escapa da mentalidade coletiva; e, por fim, o mito que cada um constrói, buscando coerência e congruência, no enfrentamento das tormentas da vida.

A crônica leva a pessoa a fazer uma ideia de momentos que lhe foram importantes e auxiliaram na sua construção: os felizes, os que provocaram sofrimentos, que criaram rupturas ou ainda os que ajudaram nas mudanças ou solidificação de etapas da vida ou de maneiras de ser. A narrativa de trabalho vai ser atravessada por uma crônica laboral. $O$ narrar a um outro interroga o sujeito, levanta aspectos esquecidos ou negados, destaca episódios que poderiam parecer sem consequências ou ainda reforça outros considerados essenciais.

A epopeia: cada sujeito, ao falar de si próprio e sobre o trabalho, também vai citar aspectos de uma epopeia de grupos ou de coletivos. Poderá mostrar como em momentos diversos da vida laboral assumiu riscos, deixando-se escapar da pressão de grupos; em outros ele teve de se submeter a formas de gestão que o aprisionavam. Citará também como participou de coletivos de trabalho, como alguns deles tenderam a posições arriscadas e tiveram tendências mais autônomas ou, em outras situaçóes, foi a heteronomia (Castoriadis, 1982) que prevaleceu. As lutas, os conflitos, as vitórias, os ganhos e as perdas estarão presentes na epopeia sobre o trabalho.

Mito: os mitos não são unicamente elaborações coletivas. Pode-se pensar que cada indivíduo e também cada sujeito trabalhador constrói seus mitos. Eles forjam uma imagem de si mesmos que permite enfrentar o mundo do trabalho. A epopeia desencadeia a construção de mitos, com diferentes níveis de solidez. Falar de si, diante de um outro, significa tocar na dimensão mítica.

A história de vida laboral, por ocasião da aposentadoria, requer o olhar sobre um longo percurso temporal, o que pode levar a discernir vários mitos. Eles podem ter se evidenciado muito fortes em várias etapas, devido a uma série de circunstâncias que precisavam ser sustentadas.

O olhar retrospectivo sobre a vida, muitas vezes, faz com que o sujeito reinterprete os mitos, visto que o que estava em jogo durante um tempo já não é mais pertinente em outra etapa. Isso se evidencia na narrativa. A época da aposentadoria faz surgir outras formações míticas, permitindo perceber 
aquelas que são explicitadas no tempo passado e as que passam a compor o presente, ou as que continuam constantes no presente. Há outras que estarão em construção, visto que a aposentadoria é um tempo entre duas importantes etapas da vida: a que se centrava predominantemente em torno do trabalho e uma outra que, tendo sido projetada ou não, começa a ser vivida, sendo então plena de desconhecimento. Paulatinamente, vai-se construindo a passagem da aposentadoria imaginária para a real. A narrativa pode criar fissuras nos mitos, trazendo para o narrador uma visão mais próxima de si, daquilo que ele está se tornando.

A aposentadoria, por ser uma etapa importante na vida das pessoas, pode trazer fortes mobilizações psíquicas, visto ser um marco, uma ruptura em uma trajetória. As significações podem tanto apelar para a liberdade quanto enfatizar a idade, o envelhecimento e os limites.

Toda história de vida vai favorecer rearranjos na crônica, na epopeia e no mito. É nesse sentido que a historicidade, como possibilidade de o sujeito se apropriar de si, sofre grande solicitação psíquica. A psicanálise poderá nos apontar a relatividade da apropriação, pois o inconsciente sempre agirá. No entanto, a historicidade permitirá a abertura a outras fantasias, a outros desejos e, consequentemente, a novas realizações. A historicidade lança um olhar ao passado e ao futuro, favorecendo modificações na relação do indivíduo com sua história (Gaulejac, Marquez \& Ruiz, 2005).

\section{CONSIDERAÇÕES FINAIS}

A história de vida, ao mesmo tempo em que é a história de um sujeito, também opera mediações entre um indivíduo e diversos grupos e organizações, enfim, com a sociedade. Essa dupla ótica sobre o sujeito e a sociedade deve ser evidenciada (Bosi, 1987). As narrativas podem ser consideradas um documento vivo de um tempo. Na perspectiva do trabalho, elas fornecem elementos que atestam as exigências feitas ao trabalhador, as formas de gestão, suas repercussões para a saúde mental e as estratégias para lidar com o mundo do trabalho. 


\section{REFERÊNCIAS}

In P. F. Bendassolli \& L. A. P. Soboll (Orgs.), Clinicas do trabalho: novas perspectivas para compreensão do trabalho na atualidade. (pp. 99-109). São Paulo: Atlas.

Bendassolli \& L. A. P. Soboll (Orgs.), Clínicas do trabalho: novas perspectivas para compreensão do trabalho na atualidade. São Paulo: Atlas

Barel, Y. (1985). La Societé du vide. Paris: Seuil.

Barus-Michel, J. (2004). O sujeito social. Belo Horizonte: Editora PUC Minas.

Bendassolli, P. F. (2009). Recomposição da relação sujeito-trabalho nos modelos emergentes de carreira. Revista de Administração de Empreses, São Paulo, 49(4), 387-400.

Billiard, I. (1997). Le grand intégrateur selon Yves Barel. In Thebaud-Mony, A. \& Appay, B. (Dirs.), Précarisation sociale, travail et santé. Paris: Institute de Recherche sur les sociétés contemporaines.

Blanché, A. (2014). La retraite une nouvelle vie. Paris: Odile Jacob.

Bosi, E. (1987). Lembranças de velhos. São Paulo: Queiroz Editor.

Carreteiro, T. C. (1993). La citoyenneté appauvrie. In V. De Gaulejac \& S. Roy (Orgs.). Sociologies cliniques. (pp. 143-147).Marseille: Hommes et perspectives.

Carreteito, T. C. \& Barros, V. A. (2011). Clínicas do trabalho: contribuições da psicossociologia no Brasil. In P. F. Bendassolli \& L. A. P. Soboll (Orgs.), Clínicas do trabalho: novas perspectivas para compreensão do trabalho na atualidade. (pp. 208-226). São Paulo: Atlas Carreteiro, T. C. (2003). História de vida: da genealogia a um estudo. Revista Psico, Porto Alegre, 34(2), 281-295.

Castoriadis, C. (1982). A instituição imaginária da sociedade. (5a ed). Rio de Janeiro: Paz e Terra. Coulon, A. (1994). L'École de Chicago. Paris : PUF.

Dejours, C. (1997). Souffrance en France. Paris: Seuil.

Enriquez E. (2003). El relato de vida: interfaz entre intimidad y vida coletiva. Perfles Latinoamericanos, Distrito Federal del Mexico, 10(21), 35-47.

Enriquez. E. (1993). Analyses cliniques dans les sciences humaines. In Enriquez, E.; Houle, G.; Rhéaume, J. \& Sévigny, R. (Orgs.). L’analyse clinique dans les sciences humaines. (pp. 13-28). Canadá: Éditions Saint-Martin. 
Freud, S. (1937/1975). Construções em análise. In Salomão, J. (Trad.), Edição standard brasileira das obras psicológicas completas de Sigmund Freud (Vol.23, pp. 290-304). Rio de Janeiro: Imago, 1975.

Freud, S. (1905/1996). Três ensaios sobre a teoria da sexualidade. In Obras psicológicas completas: Edição Standard Brasileira. (Vol. 7). Rio de Janeiro: Imago, 1996.

Gaulejac, V., Marquez, S. R. \& Ruiz, E. T. (2005). Historia de Vida: Psicoanálisis y Sociología Clínica. México: Universidad Autónoma de Querétaro.

Gratton, E.; Laine, A.; Trekker, A. (2016). Penser l'accompagnement biographique, Belgique: Harmattan Academique.

Kohli, M. \& Künemund, H.(2012). La fin de carrière et la transition vers la retraite: les limites d'âge chronologiques sont-elles un anachronisme?. Retraite et société, 2(36), 81-107.

Méda, D. (2007). Le travail. Paris: Editora PUF. Pinto, B. O. S.; Carreteiro, T. C. \& Rodriguez, L. S. (2015). Trabalhando no "entre": a história de vida laboral como método de pesquisa em Psicossociologia. Belo Horizonte: Farol Revista de Estudos Organizacionais e Sociedade, 2, (5), p. 941-985.

Sartre, J.P. (1976). Lêtre et le néant. Paris: Gallimard. 